\title{
Association between Children's Age, Numbers of Siblings and Mental Health
}

\author{
Shin-Ling $\mathrm{Wu}^{1}$, Rohani Abdullah ${ }^{1} \&$ Sakineh Mofrad $^{2}$ \\ ${ }^{1}$ Department of Human Development and Family Studies, Faculty of Human Ecology, University of Putra \\ Malaysia (UPM), Malaysia \\ ${ }^{2}$ School of Health and Natural Sciences, Sunway University, Malaysia \\ Correspondence: Rohani Abdullah, Department of Human Development and Family Studies, Faculty of Human \\ Ecology, University of Putra Malaysia (UPM), Malaysia. Tel: 60-17-247-9392. E-mail: rohani_safri@yahoo.com
}

Received: June 12, 2012 Accepted: July 9, 2012 Online Published: October 18, 2012

doi:10.5539/ass.v8n13p95 URL: http://dx.doi.org/10.5539/ass.v8n13p95

\begin{abstract}
This study was designed to examine the association between age, numbers of siblings and children's mental health. The respondents were 427 children ages between 3 to 6 years old that were selected from 29 pre-schools in Malaysia. The Child Behavior Checklist 1.5-5(CBCL/1.5-5) was used to measure the children's mental health where it comprised of eight subscales. The results revealed no significant relationship between age, number of siblings and children's overall mental health score. However, findings indicated significant relationship between age and the subscale of anxious/depressed, as well as number of siblings with the attention problems subscale. Research examining children's mental health should include a diversity of measure to identify the risk factors of mental health in order to create effective intervention and prevention programs.
\end{abstract}

Keywords: mental health, children, siblings

\section{Introduction}

Mental health problems in young children are gaining more attention from the society. In the recent years, it is estimated that approximately 20 percent of children suffer from problems related to mental health in the western countries (Bayer, Hiscock, Ukoumunne, Price, \& Wake, 2008), due to increase emphasis put on children in terms of upbringing and academic achievement. Such emphasis may have emerged from the cultural view that children are the ones relied on to bring about wealth and glory to the family (Teoh \& Rose, 2001).

As children from birth till seven years old face more emotional and behavioral challenges than before, mental health services, scientific research, and intervention in child-related areas have expanded considerably. Consequently, mental health status among children has become a distinct field. Even so, research on children's mental health problems particularly among younger children remains vastly explored. It is difficult to detect mental health problems in children especially in young children as their development is very complex (Gelfand $\&$ Drew, 2003). In addition, it is important to delineate mental health problems among children of varied age groups, as children of different ages have different development tasks and needs.

Studies showed that mental health in adult originated early in life and it has a long lasting effect in adult (Gelfand \& Drew, 2003; Kessler et al., 2007). Even though children's mental health is gaining more attention, its effective intervention and prevention are still limited. Identification of risk factors of mental health and effective intervention and prevention are very important to avoid later adult mental health problems and to improve well-being (Kieling et al., 2011).

Although various researches have been conducted on mental health problems, the coverage on risk factors is still limited especially in terms of the developmental ages and number of siblings. The risk factors of mental health include parental influence (Belsky, Bell, Bradley, Stallard, \& Stewart-Bro, 2006; Xing, Wang, Zhang, He, \& Zhang, 2011; Gelfand \& Drew, 2003), demographic background such as socioeconomic status (Davis, Sawyer, Lo, Priest, \& Wake, 2010; Belsky et al., 2006), age (Kieling et al., 2011; Kessler et al., 2007), culture (Mash \& Wolfe, 2010), gender (Patel \& Kleinman, 2003), siblings (Brody, 2004; Patel \& Kleinman, 2003).

Due to the limited study regarding children's mental health in terms of age and number of siblings, this study aims to examine the association between children's age, numbers of siblings and mental health. Based on 
research, children under the aged of seven are more vulnerable, compared with children in other age groups. Their mental health problems may intensify into psychotic disorders when they grow older (Gelfand \& Drew, 2003). Moreover, siblings play an important role in a child's life-span development. Siblings act as a modeling figure as well as playmate and expressive center for a child. Beside parents, siblings have the most contact with a child and they affect his/her language, cognitive, and emotional development, and behavior outcomes (Brody, 2004). The number of siblings in a family also affects a child indirectly, as their parents need to pay equal attention and love to all of the children. Parental failure to treat their children equally, may lead to negative consequences on the child who is neglected or being too protective (Wicks-Nelson \& Israel, 2009). Thus, it is crucial to measure both children's age and the numbers of siblings a child has in terms of mental health issue.

\section{Methodology}

\subsection{Sample and Procedures}

The respondents consisted of 427 children ages ranged from 3 to 6 years, who are randomly selected from 29 pre-schools in Malaysia. Parents were given one week duration to answer the questionnaire regarding their children's mental health.

\subsection{Measures}

The Child Behavior Checklist 1.5-5(CBCL/1.5-5) (Achenbach \& Rescorla, 2000) is a parent-report questionnaire consists of 100-items, standardized to measure behavioral and emotional problems in children. This scale scored on a three-point scale ranging from 0 for not true, 1 for somewhat or sometimes true and 2 for very true or often true. The CBCL scale has eight subscales which are emotionally reactive, anxious/depressed, somatic complaints, withdrawn, sleep problems, attention problems, aggressive behavior, and other problems. Higher scores indicate greater intensity of behavioral and emotional problems. In the present study, the overall Cronbach's alpha for the CBCL scale was found to be .951 .

\section{Results}

Data were analyzed using SPSS to calculate the descriptive and inferential statistics. Correlations are run to examine the association between age and number of siblings with the eight subscales and total score of Child Behavior Checklist.

Data were available for 427 children (205 male and 222 female) aged ranged from 3 to 6 years with a mean age of 4.5 years. A large proportion of the respondents had 2 siblings (35.1\%), followed by having 4 and above siblings (30.9\%), 3 siblings (26.2\%), and lastly the least is with only 1 sibling $(7.7 \%)$.

Table 1. Mean and standard deviation for CBCL total score and subscales

\begin{tabular}{lcc}
\hline \multicolumn{1}{c}{ Scales } & Mean & Standard Deviation \\
\hline CBCL total score & 79.07 & 34.23 \\
Emotionally reactive & 8.06 & 4.28 \\
Anxious/depressed & 7.25 & 3.64 \\
Somatic complaints & 6.73 & 4.66 \\
Withdrawn & 5.62 & 3.86 \\
Sleep problems & 4.33 & 4.87 \\
Attention problems & 4.87 & 2.03 \\
Aggressive behavior & 19.22 & 8.78 \\
Other problems & 22.99 & 10.68 \\
\hline
\end{tabular}

The borderline and clinical cut-off points for the Child Behavior Checklist are the 93rd and 97th percentile of the normal sample. As shown in table 1, all the respondents in this study score within the normal range. The mean and standard deviation for the total $\mathrm{CBCL}$ score were $\mathrm{M}=79.07$ and $\mathrm{SD}=34.23$. The mean and standard deviation for CBCL subscales are presented in Table 1. 
Table 2. Correlation between age, numbers of siblings, and CBCL total score and subscales

\begin{tabular}{lcccc}
\hline \multicolumn{1}{c}{ Scales } & \multicolumn{2}{c}{ Age } & \multicolumn{2}{c}{ Numbers of siblings } \\
\cline { 2 - 5 } & $\mathrm{r}$ & $\mathrm{p}$ & $\mathrm{r}$ & $\mathrm{p}$ \\
\hline CBCL total score & -.007 & .888 & -.005 & .924 \\
Emotionally reactive & .070 & .151 & .034 & .486 \\
Anxious/depressed & $.105^{*}$ & .031 & .008 & .860 \\
Somatic complaints & -.047 & .335 & -.039 & .416 \\
Withdrawn & .060 & .217 & .063 & .192 \\
Sleep problems & .003 & .948 & -.025 & .606 \\
Attention problems & .055 & .258 & $.123^{*}$ & .010 \\
Aggressive behavior & -.068 & .163 & -.049 & .312 \\
Other problems & -.042 & .384 & -.012 & .797 \\
\hline
\end{tabular}

* Correlation is significant at the 0.05 level (2-tailed)

Table 2 showed the correlation results between age, numbers of siblings, children's mental health total score and subscales. The correlation result revealed that there is no significant relationship between age and children's mental health total score. In terms of subscales, there is a significant relationship between anxious/depressed subscale and age $(r=.105, \mathrm{p}<.05)$ where older children tend to be more anxious and depressed. Numbers of siblings also do not have a significant relationship with children's mental health. However, the numbers of siblings and attention problems subscale are significantly correlated $(\mathrm{r}=.123, \mathrm{p}<.05)$, as children faced more attention problems if they have higher number of siblings in their family.

\section{Discussion and Conclusion}

In this study, all of the children score within the normal range, which means none of the children has mental health problems. However, the findings are not in line with the previous research where approximately 20 percent of the children faced depressive problem (Teoh, 2010).

Moreover, there were studies which revealed that normal children felt anxiety and depressed in daily circumstances. Some anxiety in children is good as it involves an immediate reaction to perceived danger or threat and adapt accordingly. However, too much anxiety results in negative consequences (Mash \& Wolfe, 2010). Also, older children tend to be more anxious and depressed, compared to the younger ones (Teoh \& Rose, 2001).

Children generally face more attention problems, when the number of siblings in the family increases. In contrast, another study shows that children with more siblings have fewer behavioral problems (Carlson \& Corcoran, 2001). According to a research by Brody (2004), children with older siblings received different treatment from their parents where the older siblings teach and take care of the younger siblings. In consequence, under certain circumstances, both the older and younger siblings face emotional and behavior problems due to the different attention gained from their parents, especially those that get less favorable treatment from their parents.

While the present study provides useful information to the existing data, it shows no significant relationship between age, number of siblings, and children's mental health total score. The findings in this study are in contrast with other previous research findings. This may due to different context or other cofounding variables that may affect the outcome of the study. Therefore, more evidence-based studies must be conducted with a diversity of measure in order to identify the various risk factors of children's mental health. For example, socialization practices may affect the mental health result. Also, this study is based on a single source. Future studies may also study on the effective prevention and intervention strategies, which are appropriate for different age groups in order to identify the problems children facing and to promote children well-being (Teoh, 2010).

\section{Acknowledgments}

We would like to thank the administered officers at University Putra Malaysia, PERMATA agency, and KEMAS preschool teachers for providing us information about the preschoolers and allowing this research to be run. We also appreciate the parents for participating in this research. This study was supported by the Federal Research Grant (FRGS/2/2010/SS/UPM/02/3) from University Putra Malaysia. 


\section{References}

Achenbach, T. M., \& Rescorla, L. A. (2000). Manual for the ASEBA Preschool Forms \& Profiles. Burlington, VT: University of Vermont Department of Psychiatry. CBCL 1.5 5/Reliability/Validity/C-TRF/DSM/Factor Analysis/Language Development Survey (LDS).

Bayer, J. K., Hiscock, H., Ukoumunne, O. C., Price, A., \& Wake, M. (2008). Early childhood aetiology of mental health problems: a longitudinal population-based study. Journal of Child Psychology and Psychiatry, 49(11), 1166-1174.

Belsky, J., Bell, B., Bradley, R. H., Stallard, N., \& Stewart-Bro, S. L. (2006). Socioeconomic risk, parenting during the preschool years and child health age 6 years. European Journal of Public Health, 17(5), 508-513. http://dx.doi.org/10.1093/eurpub/ck1261

Brody, G. H. (2004). Siblings' direct and indirect contributions to child development. Current Directions in Psychological Science, 13(3), 124-126. http://dx.doi.org/10.1111/j.0963-7214.2004.00289.x

Carlson, M. J., \& Corcoran, M. E. (2001). Family Structure and Children's Behavioral and Cognitive Outcomes. Journal of Marriage and Family, 63(3), 779-792. http://dx.doi.org/10.1111/j.1741-3737.2001.00779.x

Davis, E., Sawyer, M. G., Lo, S. K., Priest, N., \& Wake, M. (2010). Socioeconomic risk factors for mental health problems in 4-5-year-old children: Australian population study. Academic Pediatric Association, 10(1), 41-47. Retrieved from http://repository.ied.edu.hk/dspace/handle/2260.2/11000 http://dx.doi.org/10.1016/j.acap.2009.08.007

Gelfand, D. M., \& Drew, C. J. (2003).Understanding child behavior disorders (4th ed.). United States: Thomson Learning.

Kessler et al. (2007). Lifetime prevalence and age-of-onsetdistributions of mental disorders in the World Health Organization's World Mental Health Survey Initiative. World Psychiatry, 6(3), 168-176.

Kieling et al. (2011). Child and adolescent mental health worldwide: Evidence for action. Lancet, 378, 1515-1525. http://dx.doi.org/10.1016/S0140-6736(11)60827-1

Mash, E. J., \& Wolfe, D. A. (2010). Abnormal Child Psychology (4th ed.). Wadsworth: Cengage Learning.

Patel, V., \& Kleinman, A. (2003). Poverty and common mental disorders in developing countries. Bulletin of the World Health Organization, 81(8), 609-615.

Teoh, H. J. (2010). A survey of urban child and adolescent mental health problems in an urban Malaysian population. Malaysian Journal of Psychiatry, 19(1).

Teoh, H. J., \& Rose, P. (2001). Child mental health: Integrating Malaysian needs with international experiences. In A. Haque (Ed.), Mental health in Malaysia (pp. 103-121). Kuala Lumpur: University of Malaya Press.

Wicks-Nelson, R., \& Israel, A. C. (2009).Abnormal child and adolescent psychology (7th ed.). United States: Pearson Prentice Hall.

Xing, X., Wang, M., Zhang, Q., He, X., \& Zhang, W. (2011). Gender differences in the reciprocal relationships between parental physical aggression and children's externalizing problem behavior in China. Journal of Family Psychology, 25(5), 699-708. http://dx.doi.org/10.1037/a0025015 